\title{
Aksentuasi Bibliotherapy di Perpustakaan Perguruan Tinggi
}

\author{
Saleha Rodiah \\ Program Studi Ilmu Informasi dan Perpustakaan \\ Fakultas Ilmu Komunikasi - Universitas Padjadjaran \\ Email: saleha_rodiah@yahoo.com
}

\begin{abstract}
Abstrak - Perpustakaan perguruan tinggi berperan dalam membantu mencerdaskan bangsa dalam segala aspek kehidupan, serta dapat berperan aktif dalam melayani pemustakanya. Dalam hal ini mahasiswa melalui kegiatan bibliotherapy atau terapi pustaka. Konsep Bibliotheraphy bukanlah merupakan konsep baru dalam bidang kepustakawanan. Layanan bibliotherapy dilakukan di perpustakaan perguruan tinggi dilaksanakan untuk membantu masalah mahasiswa yang bersifat akademik maupun non akademik yang ditengarai dapat mengganggu kelangsungan studinya, dengan fasilitator pustakawan terlatih sebagai biblioterapis. Kegiatan bibliotherapy dapat diterapkan di perpustakaan perguruan tinggi dengan memperhatikan aspek-aspek yang mendukung terselenggaranya bibliotherapy secara efektif.
\end{abstract}

Kata kunci: Bibliotheraphy, Perpustakaan Perguruan Tinggi, Membaca

\begin{abstract}
University libraries play an important role in educating the nation in all aspects of life, and can actively play a role in user's services, in this case for students through bibliotherapy activities or book therapy. The concept of bibliotherapy is not new in the field of librarianship. Bibliotherapy services are performed in university libraries by a trained librarian as facilitator who acts as bibliotherapist to assist students regarding their academic and non-academic problems which can obstruct the continuity of their study. Bibliotherapy activities can be implemented in university libraries by giving attention to aspects which effectively support the execution of bibliotheraphy.
\end{abstract}

Keywords : Bibliotheraphy, University Libraries, Reading

\section{PENDAHULUAN}

Peran perpustakaan di tengah masyarakat masih terasa meski acapkali tidaklah terekspos dengan baik. Namun, hal ini tidak menyurutkan langkah para ilmuwan dan praktisi perpsutakaan dengan segala kemampuannya menjadikan citra perpustakaan lebih baik lagi dan manfaatnya dapat diakses oleh masyarakat dalam jangkauan yang lebih luas. Berdasarkan klasifikasi jasa sesuai tujuan organisasinya perpustakaan dikategorikan sebagai non-profit services, sebagaimana sekolah, yayasan dana bantuan, panti asuhan dan museum (Lovelock, dalam Tjiptono dan Chandra 2007, hal.15). Tentu bukanlah sebuah hal mengherankan apabila upaya diversifikasi layanan perpustakaan terus dilakukan untuk mengikuti perkembangan teknologi informasi dan pemenuhan kebutuhan masyarakat terhadap informasi, serta meningkatkan tingkat kunjungan ke perpustakaan sebab pada Pasal 3 Undang-undang Republik Indonesia No. 43 Tahun 2007 tentang Perpustakaan tercantum: "perpustakaan berfungsi sebagai wahana pendidikan, penelitian, pelestarian, informasi dan rekreasi untuk meningkatkan kecerdasan dan keberdayaan bangsa". Selain itu pada Pasal 4 disebutkan bahwa "perpustakaan bertujuan memberikan layanan kepada pemustaka, meningkatkan kegemaran membaca, serta memperluas wawasan dan pengetahuan untuk mencerdaskan kehidupan bangsa."

Fungsi dan tujuan perpustakaan tersebut berada dalam tataran normatif berdirinya suatu perpustakaan. Hingga kini upaya memenuhi dan menjangkau format ideal suatu perpustakaan menjadi sasaran umum kegiatan bagi setiap perpustakaan, walaupun dalam bentuk pemahaman dan variasi layanan yang berbeda-beda, tidak terkecuali perpustakaan perguruan tinggi. Perpustakaan perguruan tinggi dibentuk dalam melaksanakan Tridharma perguruan tinggi yang terdiri dari pendidikan, penelitian, dan pengabdian kepada masyarakat. Perguruan tinggi dapat berbentuk universitas, akademi, sekolah tinggi, ataupun institut. Keberadaan perpustakaan perguruan tinggi sangat penting bagi terciptanya masyarakat akademis sehingga selayaknya memiliki fasilitas yang memadai dan berfungsi dengan baik serta dapat dimanfaaatkan oleh pemustakanya secara maksimal.

Upaya mewujudkan layanan perpustakaan dalam memenuhi kebutuhan pemustaka menjadi tugas mulia yang diemban perpustakaan perguruan tinggi sebagai jantungnya suatu perguruan tinggi, sebagaimana pendapat Sutarno (2005, hal. 61) yang menyebutkan bahwa salah satu tugas perpustakaan adalah memberikan layanan informasi yang ada untuk diberdayakan kepada masyarakat pengguna, sehingga 
perpustakaan menjadi agen perkembangan ilmu pengetahuan dan informasi, teknologi dan budaya masyarakat.

Hal tersebut di atas sejalan dengan tujuan Negara Indonesia merdeka yaitu mencerdaskan kehidupan bangsa. Bangsa yang cerdas mempunyai ciri antara lain selalu belajar dan meningkatkan kemampuan, karena kecerdasan mempunyai aspek yang lebih luas meliputi kecerdasan intelektual, spiritual, personal, dan kecerdasan sosial. Kecerdasan paripurna inilah yang dapat membawa masyarakat Indonesia kepada kemajuan dan kesejahteraan yang sebenarnya.

Selain mencerdaskan dan sebagai sumber pembelajaran yang berlaku seumur hidup, peran perpustakaan juga bisa menjadi tempat tumbuhnya modal sosial (social capital). Pada tempat tersebut, masyarakat dapat berdiskusi, bertukar pikiran, memberi pelajaran atau mempelajari keterampilan dari seseorang dan menciptakan jaringan sosial. Dari sistem sosial seperti itu, diantara mereka akan tumbuh perasaan saling percaya, saling menghargai dan menghormati (Laksmi 2007, p.147).

Untuk itu keberadaan perpustakaan di perguruan tinggi sebagai jantung yang memberi semangat bagi terselenggaranya layanan perpustakaan yang dapat memenuhi kebutuhan pemustakanya, perlu direvitalisasi dengan cara menghidupkan kembali peran dan fungsi perpustakaan perguruan tinggi dengan kegiatan-kegiatan nyata yang bermanfaat bagi pemustakanya dalam meningkatkan keteram pilan hidup dan pengembangan dirinya.

\section{Mengapa Biblioterapi?}

Kelompok pemustaka perpustakaan perguruan tinggi antara lain adalah mahasiswa. Pada umumnya usia mahasiswa berada dalam rentang 17 sampai 25 tahun yang dikategorikan oleh Ingresoll dalam (Agustiani 2006) berada pada masa remaja akhir. "Masa ini ditandai oleh persiapan akhir untuk memasuki peran-peran orang dewasa. Selama periode ini remaja berusaha memantapkan tujuan vokasional dan mengembangkan sense of personal identity. Keinginan yang kuat untuk menjadi matang dan diterima dalam kelompok teman sebaya dan orang dewasa."

Selain itu, mahasiswa untuk mendapatkan perguruan tinggi yang bermutu acapkali harus menjalani pendidikannya jauh dari tempat tinggal asalnya dan harus menetap di rumah keluarga lain, asrama atau kamar sewaan. Dengan kepribadian yang belum stabil, konsep pendidikan yang berbeda dengan masa sekolah menengah, lingkup pergaulan baru serta tuntutan masyarakat dengan status "mahasiswa" yang apabila kondisi ini tidak dintisipasi dengan baik dapat menimbulkan gejolak yang disebut sebagai gegar budaya (culture shock).

Untuk itu mahasiswa dalam proses pembelajaran dan pergaulan sehari-harinya harus berupaya untuk bisa menyesuaian diri dengan lingkungan sosial yang baru agar tujuan pembelajaran di perguruan tinggi dapat tercapai dengan sebaik-baiknya. Schneiders dalam Agustiani (2006, hal.146) mengemukakan bahwa,"penyesuaian diri merupakan suatu proses yang mencakup respon-respon mental dan tingkah laku, yang merupakan usaha individu agar berhasil mengatasi kebutuhan, ketegangan, konflik dan frustasi yang dialaminya sendiri."

Setiap mahasiswa tentu mempunyai cara tersendiri dalam merespon suatu konflik dan pemenuhan kebutuhannya, begitupula tatkala menunjukkan perilaku dalam proses kegiatan penyesuaian diri dengan dunia perguruan tinggi yang berbeda-beda, menurut Agustiani (2006, hal.48) dapat dipengaruhi oleh beberapa faktor, yaitu:

1. Faktor kondisi fisik, yang meliputi faktor keturunan, kesehatan, bentuk tubuh dan hal-hal lain yang berkaitan dengan fisik.

2. Faktor perkembangan dan kematangan, yang meliputi perkembangan intelektual, sosial, moral dan kematangan emosional.

3. Faktor psikologis, yaitu faktor-faktor pengalaman individu, frustasi dan konflik yang dialami, dan kondisikondisi psikologis seseorang dalam penyesuaian diri.

4. Faktor lingkungan, yaitu kondisi yang ada pada lingkungan, seperti kondisi keluarga, kondisi rumah, dan sebagainya.

5. Faktor budaya, termasuk adat istiadat dan agama yang turut mempengaruhi penyesuaian diri seseorang.

Setiap mahasiswa akan berupaya bisa mengatasi dengan baik konflik yang terjadi dalam proses pembelajaran dan komunikasi interpersonalnya hingga tidak mengganggu nilai akademik, interaksi sosial dan kejiwaannya. Namun, adakalanya proses penyesuaian diri tersebut tidak berhasil, sebagai contoh masalah yang bersangkut dengan pemilihan teman bergaul yang kurang tepat bisa menyebabkan depresi atau nilai Indeks Prestasi (IP) yang rendah. Biasanya dosen wali dengan kewenangannya berupaya mendukung agar mahasiswa tersebut dapat menyelesaikan perkuliahan tepat waktu dan sehat secara psikisnya. Selain itu di Fakultas ataupun Universitas terdapat unit yang menangani mahasiswa yang mempunyai masalah non akademis yang dapat menghambat kelangsungan studinya, seperti Tim Pelaksana Bimbingan Konseling (TPBK).

Jasa layanan perpustakaan mempunyai tingkat interaksi yang tinggi dengan pemustakanya. Perpustakaan perguruan tinggi memposisikan diri antar muka (interface), antara pemustaka, dalam hal ini mahasiswa dan sumber informasi yang dimiliki perpustakaan. Oleh karena itu selayaknya pihak perpustakaan dalam upayanya memberdayakan pemustaka serta mendukung tujuan pendidikan nasional, bisa mengambil peran strategis untuk mengakomodasi masalah mahasiswa tersebut melalui layanan bibliotheraphy atau terapi pustaka dengan dukungan para psikolog atau pustakawan yang telah mendapatkan pelatihan sebagai terapis. 
Layanan bibliotheraphy ini diibaratkan menghidupkan kembali kedigjayaan perpustakaan sebagai pusat peradaban karena "metode bibliotheraphy merupakan sebuah konsep tua dalam ilmu perpustakaan" (Eliasa 2007). Konon menurut Zulaeha (2012) "bibliotherapy telah dikenal sejak zaman Yunani Kuno, tepatnya di atas gedung Perpustakaan Thebes terdapat patung yang melukiskan orang yang tengah bosan dan dibawahnya diketemukan manuskrip yang berbunyi "the healing place of the soul" (tempat penyembuhan jiwa)."

Secara etimologis, istilah bibliotherapy berasal dari bahasa Yunani, yaitu biblus berarti buku, dan therapy yaitu upaya bantuan psikologis, oleh karena itu bibliotherapy dapat didefinisikan sebagai penggunaan buku-buku untuk membantu memecahkan masalah. Selain itu Laksmi (2006, p. 148) menyebutkan bahwa :

Membaca buku-buku tertentu dapat dijadikan terapi, disebut sebagai bibliotherapy, yaitu suatu bacaan bisa memberi inspirasi untuk mengatasi persoalan hidup dan membantu berpikir positif." Untuk memperoleh manfaat di atas, kegiatan membaca bukan hanya sekedar membaca, menghubungkan kata perkata, dan sekedar mengetahui isi teks, tapi mencermati dan menganalisis bacaan sehingga diperoleh pemahaman yang mendalam.

Kegiatan terapi dengan menggunakan media buku dipilih karena buku merupakan bahan pustaka yang banyak dikoleksi oleh perpustakaan perguruan tinggi dalam berbagai subjek. Selain memiliki kemampuan membaca yang harus dimiliki partisipan terapi, buku merupakan media massa yang mudah diperoleh serta dalam penggunaannya tidak memerlukan alat bantu khusus. Purwono (2009, hal.2) menyebutkan bahwa: "ditinjau dari fungsinya buku dapat didefinisikan sebagai alat komunikasi tulisan yang dirakit dalam satu satuan atau lebih, agar pemaparannya dapat bersistem, dan isi maupun perangkat kerasnya dapat lebih lestari."

\section{Menerapkan Bibliotherapy di Perpustakaan Perguruan Tinggi}

Berry dalam Fathiyah dalam Eliasa (2007) mengkategorikan bibliotherapy dalam dua tipe, yaitu:

\section{a. Tipe klinis.}

Merupakan bentuk psikoterapi yang dilaksanaan oleh profesi kesehatan termasuk psikiater, psikolog, pekeja sosial, dan sebagainya. Fasilitatornya adalah seorang terapis dan partisipannya adalah orang yang sakit. Adapun tujuannya adalah membantu klien untuk memperoleh keadaan menjadi lebih baik. Dalam tipe ini fungsi terapi adalah membentuk kehidupan individu. Seorang pasien yang menderita penyakit atau mengalami cacat tertentu dapat merasakan suatu kepuasan tertentu dengan membaca biografi atau cerita keberhasilan penyesuaian diri dari orang yang mengalami penderitaan yang sama.

\section{b. Tipe Pendidikan atau humanistik.}

Merupakan tipe terapi pustaka yang dilaksanakan oleh konselor, guru, dan petugas perpustakaan dalam setting pendidikan. Fasilitatornya adalah pimpinan atau manajer kelompok. Adapun partisipan pada terapi pustaka tipe ini adalah orang yang sehat fisiknya, misalnya siswa.

Kegiatan bibliotherapy di perpustakaan perguruan tinggi dikategorikan sebagai tipe pendidikan atau humanistik. Fasilitator bibliotherapy di perpustakaan perguruan tinggi ini adalah pustakawan yang ditelah dilatih sebagai terapis oleh psikolog yang mendalami konseling. Partisipan bibliotherapy dalam hal ini adalah mahasiswa yang mempunyai masalah baik akademik maupun non akademik yang dapat mengganggu kelangsungan studinya.

Bibliotheraphy yang dilakukan di perpustakaan perguruan tinggi ini adalah membantu mahasiswa mencapai tujuan pembelajarannya serta proses aktualisasi diri di tengah masyarakat. Sehingga mahasiswa tersebut dengan beberapa sesi terapi membaca dan mendiskusikan buku dengan subjek tertentu yang menjadi koleksi perpustakaan bersama kelompok dan dibimbing pustakawan atau biblioterapis dapat terbuka wawasan serta memahami masalah yang sedang dihadapinya hingga dengan kemampuan mandirinya dapat menuntaskan masalah tersebut dengan baik.

Sebagaimana dijelaskan Myracle dalam Yusup dan Taharem (2008) bahwa :

Sebagai bentuk terapi, bibliotherapy bertujuan untuk mengembangkan konsep diri klien dan untuk meningkatkan pemahaman tentang perilaku manusia dan motivasi, juga melayani tujuan untuk menumbuhkan penilaian diri individu secara jujur dan membuka tempat bagi klien untuk menemukan minat di luar diri. Tujuan yang paling penting dari bibliotherapy adalah membantu klien untuk mendiskusikan masalah atau situasi yang lebih bebas, dan dalam prosesnya, ia akan mampu mengurangi tekanan emosional atau mental atau situasi stres lainnya.

Kegiatan membaca adalah proses yang dinamis dan diyakini dapat menjadi sebuah terapi. Ketika mahasiswa dengan keinginannya ataupun dengan saran pustakawan terapis atau psikolog konselor untuk membaca buku bagus yang sesuai, maka kebutuhan serta masalah yang membelit terkadang dengan sendirinya menghilang. Hal ini, disebabkan adanya pelibatan secara emosional ke dalam perjuangan dan upaya si tokoh. Sehingga ketika selesai membaca dan ataupun dengan mendiskusikannya dalam kelompok bersama terapis di perpustakaan, mahasiswa akan memperoleh wawasan baru mengenai situasi dan upaya untuk menangani masalah yang sedang dihadapinya. Selanjutnya dapat memberi pencerahan dan harapan baru sehingga mahasiswa tersebut dapat melanjutkan studi atau memecahkan masalah yang dihadapinya dengan baik. 
Crothes (Shechtman, dalam Eliasa 2007) menggambarkan ketika pembaca membaca bukunya, akan menemukan diri ketika memasuki dunia yang dijelaskan dalam halaman-halaman buku tersebut, juga muncul ketika melihat adegan film yang baik, kemudian terlibat pada karakter di dalamnya. Sehingga ketika 'aktor' mengalami perasaan senang atau sedih, maka pembaca akan menderita atau bahagia; pembaca menangis dengan karakter menderita. Crothes menegaskan bahwa dengan membaca berkualitas tinggi maka akan menumbuhkan wawasan baru dan ide untuk kehidupan, kemudian terjadi sebuah proses penyembuhan yang dapat memperkaya diri pembaca.

Menurut salah seorang biblioterapis yang juga seorang pustakawan, Catherine Morris dalam Zulaeha (2012)

"Bibliotherapy ditujukan bagi penderita depresi dan kegelisahan ringan. Ia menganjurkan bibliotherapy berdasarkan pengalamannya selama mengelola perpustakaan. Catherine juga banyak mendengar komentar dari pengunjung yang memperoleh keceriaan kembali setelah mereka membaca kisah tertentu. Mereka merasa lebih bersemangat setelah mengetahui bahwa masalah yang dihadapi ternyata jauh lebih ringan dibanding kisah yang dibacanya."

Penerapan bibliotherapy di perpustakaan perpustakaan perguruan tinggi tidak terbatas dalam bentuk membaca buku dan mendiskusikannya, sebagaimana disebutkan Shechtman dalam Eliasa (2007) yang menekankan bahwa "Bibliotherapy entails the use of literature for therapeutic purposes and it includes listening to stories and poems, watching films, and looking at pictures. It is a playful, engaging, and fun process." Shechtman mengkombinasikan kegiatan mendengarkan cerita, membaca puisi, menonton film dan gambar dilakukan di dalam rangkaian bibliotherapy, sehingga aktivitas berjalan menarik dan menyenangkan.

Efektivitas bibliotheraphy sebagai terapi yang mudah, murah dan dapat dilakukan kapan saja dan merangsang mahasiswa untuk berpikir dan berpartisipasi secara aktif. Terdapat beberapa penelitian yang telah menguji efektivitas bibliotheraphy ini, antara lain disebutkan Myracle dalam Yusup dan Taharem (2008) bahwa "bibliotherapy telah berhasil sebagai sarana membantu anak-anak dan remaja agar merasa menjadi lebih baik berkaitan dengan diri mereka sendiri. Dengan sikap positif yang mereka kembangkan, mereka menjadi lebih mudah beradaptasi dan siap menghadapi masalah, antara lain masalah penampilan, popularitas dan prestasi akademik."

Pihak perpustakaan perguruan tinggi dapat memulai menerapkan bibliotheraphy sebagai layanan di perpustakaan, antara lain dengan:

\section{Melakukan komunikasi} pimpinan perguruan tinggi

organisasi

dengan

Sebagai unit pelaksana teknis dari suatu perguruan tinggi, perpustakaan perlu mengajukan usulan dan proposal kegiatan sebagai bahan pertimbangan mengenai pentingnya layanan bibliotheraphy sebagai sarana membantu mahasiswa agar memiliki kecerdasan paripurna dan menjadi insan mandiri pembaharu.

2. Melakukan koordinasi dan kerjasama dengan Tim Pelaksana Bimbingan dan Konseling (TPBK)

Perpustakaan perlu menjalin hubungan baik dengan para pelaksana bimbingan konseling, baik di tingkat fakultas maupun universitas untuk mendapatkan bentuk-bentuk masalah yang umumnya dialami oleh mahasiswa dan bekerjasama membentuk tim yang solid dengan tujuan mendukung mahasiswa agar sukses di bidang akademik serta sehat secara psikologisnya

\section{Membuat Model bibliotheraphy}

Melakukan komunikasi intensif dengan dosen-dosen dari Fakultas Psikologi atau konselor yang aktif melakukan bimbingan dan konseling, khususnya terhadap remaja dan dewasa awal serta mempraktikkan model bibliotheraphy yang tepat untuk pemecahan masalah, misalnya model bibliotherapy untuk meningkatkan self-esteem. Dalam hal ini termasuk pelatihan untuk menjadi fasilitator bagi pustakawan atau ketua kelompok mengenai teknik bibliotheraphy sehingga dapat menjadi bibliterapis yang mumpuni serta penyediaan metode klasikal atau individu.

\section{Pengembangan koleksi perpustakaan}

Dengan adanya diversifikasi layanan ini, pihak perpustakaan lebih memperhatikan karakteristik pemustakanya, dalam hal ini mahasiswa yang mempunyai masalah tertentu, kemudian seleksi bahan pustaka dengan memprioritaskan buku-buku yang bersifat self-help dan biografi, seperti buku : Chicken Soup for The Soul, Terapi Berpikir Positif. Selanjutnya, melakukan pengadaan bahan pustaka berupa buku teks, novel dan jenis bacaan lainnya dengan subjek yang disesuaikan dengan kebutuhan terapi pemustaka.

\section{Pembuatan Alat Ukur Kegiatan}

Perpustakaan bekerjasama dengan psikolog mempersiapkan alat ukur yang sistematis untuk menilai pelaksanaan bibliotherapy sehingga tingkat kemajuannya dapat terpantau dan dijadikan sebagai bahan evaluasi serta pelaporan pada pimpinan perguruan tinggi. 


\section{Promosi Layanan Bibliotherapy}

Setelah persiapan dilakukan secara terencana dan baik, maka perpustakaan perguruan tinggi dapat melaunching layanan bibliotherapy ini dengan menggunakan media sebagai sarana promosi, antara lain press release, pamphlet, poster, website resmi fakultas atau universitas, dan jejaring sosial.

\section{PENUTUP}

Layanan bibliotherapy di perpustakaan perguruan tinggi dapat dikatakan sebagai upaya menghidupkan kembali peran perpustakaan sebagai jantung perguruan tinggi serta barometer peradaban bangsa. Perpustakaan perguruan tinggi ingin berperan aktif dan responsif dalam upaya mendukung pemustaka mahasiswa untuk memiliki jiwa yang sehat dan keterampilan hidup dalam mengatasi masalahnya, sehingga dapat menyelesaikan studinya tepat waktu, memperoleh IPK yang baik serta bermanfaat bagi masyarakatnya.

Untuk itu perpustakaan perlu mempersiapkan upaya mewujudkannya dengan konsep bibliotheraphy di perpustakaan, pelatihan pustakawan sebagai biblioterapis, pemilihan model bibliotheraphy yang tepat hingga pengembangan koleksi yang mendukung terapi. Semoga dengan layanan bibliotheraphy yang efektif dapat meningkatkan animo civitas akademika memanfaatkan fasilitas perpustakaan dan citra baik perpustakaan perguruan tinggi sebagai penyedia layanan informasi dapat tetap terjaga.

\section{DAFTAR PUSTAKA}

Agustiani, Hendriati. 2006. Psikologi Perkembangan: Pendekatan Ekologi Kaitannya dengan Konsep Diri dan Penyesuaian Diri pada Remaja. Bandung : Refika Aditama

Eliasa, Eva Emania. 2007. Bibliotherapy sebagai Sebuah Metode Tindakan yang Bermakna http://staff.uny.ac.id/sites/default/files/132318571/Mic rosoft\%20Word\%20-

\%20BIBLIOTHERAPY\%20AS\%20A\%20METHOD \%200F\%20MEANINGFUL\%20TREATMENT.pdf

Indonesia. 2007. Undang-undang Republik Indonesia Nomor 43 Tahun 2007 tentang Perpustakaan. Jakarta : Rineka Cipta

Laksmi. 2007. Tinjauan Kultural terhadap Kepustakawan : Inspirasi dari Sebuah Karya Umberto Eco. Depok : Fakultas Ilmu Budaya http://www.adk.gov.my/html/pdf/jurnal/2008/3.pdf

Purwono. 2009. Pemaknaan Buku bagi Masyarakat Pembelajar. Jakarta : Sagung Seto.

Sutarno, NS. 2005. Perpustakaan dan Masyarakat. Jakarta : Sagung Seto.

Tjiptono, Fandy dan Chandra, Gregorius. 2007. Service, Quality \& Satisfaction. Ed. 2. Yogyakarta : Andi.

Yusuf, Roselina binti \& Mohd. Shukry bin Taharem 2008.
Program with Children and Adolescents. Jurnal anti dadah Malaysia. http://www.adk.gov.my/html/pdf/jurnal/2008/3.pdf

Zulaeha,Ella. 2012. Biblioterapi: Penghalau Galau dan Depresi http://kesehatan.kompasiana.com/ kejiwaan/2012/05/21/biblioterapi-penghalaugalau-dan-depresi-464486.html

Bibliotherapy: a Tool for Primary Prevention 